Dear author,

Please note that changes made in the online proofing system will be added to the article before publication but are not reflected in this PDF.

We also ask that this file not be used for submitting corrections. 


\title{
Axisymmetric vibrations of a circular Chladni plate in air and fully submerged in water
}

\author{
Xavier Escaler ${ }^{a, *}$, Oscar De La Torre ${ }^{b}$ \\ a Centre for Industrial Diagnostics and Fluid Dynamics, Universitat Politècnica de Catalunya, Av. Diagonal 647, 08028 Barcelona, Spain \\ b Faculty of Engineering, University of Bristol, UK
}

\section{A R T I C L E I N F O}

\section{Article history:}

Received 4 January 2018

Received in revised form 30 April 2018

Accepted 31 July 2018

Available online $\mathrm{xxxx}$

\section{Keywords:}

Fluid-structure interaction

Chladni plates

Experimental modal analysis

Acoustic-structure FEM

Mode shapes

\begin{abstract}
A B S T R A C T
In this study, experimental and numerical analyses were performed to determine the effects of water loading on the axisymmetric modes of vibration of a circular plate. The plate was harmonically excited at its centre through an extension bar and its outer edge was left free. The Chladni technique, which involves exciting the plate at a resonance and waiting for sand grains sprinkled on the plate to collect along the nodal circles, was used to identify and visualize the modes both in air and fully submerged in water. Surprisingly, inverse Chladni patterns were observed in water as particles were drawn towards the zero transversal velocity radii by the induced flow. A coupled acoustic-structural finite element model was built to simulate the same modes, which had been preliminarily validated against theoretical results of a completely free edged plate. A good agreement between experimental and numerical natural frequencies and mode shapes was found. The frequency reduction ratio due to the added mass effect was around $64 \%$. Moreover, measurable differences due to fluid-structure coupling were observed in the radii of the nodal circles between corresponding dry and wet modes.
\end{abstract}

(C) 2018 Published by Elsevier Ltd.

\section{Introduction}

Starting with the pioneering work of Lindholm et al. (1965) and Blevins (1979), the fluid-structure interaction (FSI) phenomena has been the focus of many experimental, numerical and theoretical investigations. Recently, FSI problems have received much attention in the field of hydraulics due to the importance of studying the dynamic responses of pipelines and machines, as reported by Li et al. (2015) and Trivedi and Cervantes (2017), respectively. In the case of water turbines, Rodriguez et al. (2006) and Lais et al. (2009) investigated the added mass effects of water on the modal properties of complex structures such as the runners. In this sense, it is well known that the presence of a dense fluid surrounding the solid causes a reduction in the natural frequencies compared to air. In general, identical mode shapes have been assumed for a structures in air and fully submerged in water.

The authors of the present work recently became interested in the dynamic responses of bodies submerged in two-phase flows. For example, the influence of cavitation on the structural response of a hydrofoil (De La Torre et al., 2013, 2014; Liu et al., 2017) and the directional added mass effects in partially liquid-filled horizontal pipes (Escaler et al., 2017) have been experimentally and numerically studied. From these investigations, the authors of this current work have detected that small but relevant differences may exist between the mode shapes in air and in water. This observation agrees with the theoretical results of Amabili et al. (1995), Amabili et al. (1996), Amabili (1996) and Amabili and Kwak (1996) who

\footnotetext{
* Corresponding author.

E-mail addresses: xavier.escaler@upc.edu (X. Escaler), oscar.delatorre@bristol.ac.uk (O. De La Torre).
} 
compared the assumed-modes approach and the Rayleigh-Ritz method to calculate the vibrations of annular and circular plates coupled with fluids. The former approach assumes that the mode shapes are not modified by the fluid, i.e. dry and wet mode shapes are exactly the same, meanwhile the latter method removes this simplifying hypothesis. Their calculations showed that with the Rayleigh-Ritz method the nodal circles in water can change around $5 \%$ depending on the mode and the boundary conditions. Similarly, Junger and Feit (1986) noted that underwater mode shapes were slightly deformed compared to the mode shapes in air, which was likely due to modal coupling by the dense fluid. Furthermore, the differences appear considerably larger when the body is partially in contact with water and air, as presented in De La Torre et al. (2016).

The present manuscript addresses the experiments and numerical simulations used to quantify the changes in the modes of vibration of a simple structure with the addition of a surrounding fluid. Specifically, the modal vibrations of a circular Chladni plate were studied in air and completely submerged in a water tank. The idea behind this experiment was to excite the axisymmetric modes and to infer the mode shapes from the nodal circles by using the method published by Chladni (1787). Modal changes can be quantified by comparing the results from air and water along with the use of simulations.

The Chladni patterns can be generated by exciting a horizontal plate at a single vibrational mode and then waiting for sand grains scattered on the top surface to collect along the nodal lines. The Chladni technique allows for the observation of vibration modes and has been commonly used to study the frequencies of plates with different geometries and dimensions. To our knowledge, this visualization method has only been used in air, similar to the work of Rossing (1982). Therefore, the intention of this study is to validate the method for a plate submerged in still water.

Regarding alternative experimental modal test methods, Bergen and Pechersky (1991) carried out a similar investigation on submerged composite square plates using Digital Speckle Pattern Interferometry (DSPI), which is similar to holographic interferometry. Askari et al. (2013) conducted modal tests on circular plates immersed in a fluid at various depths; the plate responses were measured with a laser Doppler vibrometer through a transparent wall at the bottom of the tank, and the experimental results were used to validate a theoretical model. To infer a mode shape from the experiment, only 4 or 5 measurements (equally distributed along the radius) were presented for the axisymmetric modes with 1 and 2 nodal circles. In both of these studies, the proposed visualization methods are far more expensive and less practical than the methods used in the present study. The Chladni technique has been proved to visualize the nodal lines with a high spatial resolution.

Recently, several analytical and numerical methods have been proposed to determine the modal characteristics of circular and annular plates in fluid. In particular, Kwak and Amabili (1999) analysed theoretically the natural frequencies of free-edge annular plates fully immersed in water. Jhung et al. (2009) developed an analytical method to assess a perforated plate in contact with or submerged in fluid. Garrido-Mendoza et al. (2013) studied the hydrodynamic coefficients of added mass and damping of an oscillating disk approaching a seabed using OpenFOAM ${ }^{\circledR}$ software. Finally, Gascón-Pérez and García-Fogeda (2015) developed a method to compute the natural frequencies and acoustic damping ratio of a circular plate surrounded by a compressible fluid of arbitrary density. In our study, we have used the acoustic-structural finite element analysis (FEA) tool available in ANSYS ${ }^{\circledR}$ Mechanical, which takes into account the FSI phenomena.

\section{Axisymmetric vibrations of a circular plate completely free}

Leissa (1969) and Leissa and Narita (1980) calculated the natural frequencies of circular plates in a vacuum by solving the classical differential equation of motion for the transverse displacement of a plate given by

$$
D \nabla^{4} w+\rho_{A} \frac{\partial^{2} w}{\partial t^{2}}=0
$$

where $\rho_{A}$ is the area density of the plate, $t$ is the time, $\nabla^{4}=\nabla^{2} \nabla^{2}$, where $\nabla^{2}$ is the Laplace operator and $D$ is the flexural rigidity defined by

$$
D=\frac{E h^{2}}{12\left(1-v^{2}\right)} \text {. }
$$

For free vibration, the motion can be expressed as

$$
w=W \cos \omega t
$$

where $\omega$ is the angular frequency, and $W$ is a function of the position coordinates. Substituting Eq. (3) into Eq. (1) yields

$$
\left(\nabla^{4}-k^{4}\right) W=0
$$

where $\mathrm{k}$ is a parameter of convenience defined as

$$
k^{4}=\frac{\rho \omega^{2}}{D}
$$

For a solid circular plate (having no internal holes) with the polar coordinate system origin coincident with the centre of the plate, the solution to Eq. (4) for values of $n$ from 0 to $\infty$ becomes

$$
W_{n}=\left[A_{n} J_{n}(k r)+C_{n} I_{n}(k r)\right] \cos n \theta
$$


Table 1

Values of $\lambda^{2}$ for axisymmetric vibrations of a circular plate completely free and $v=1 / 3$ from Leissa and Narita (1980).

\begin{tabular}{|c|c|c|c|c|c|c|}
\hline Mode & $s 1$ & $s 2$ & $s 3$ & $s 4$ & $s 5$ & $s 6$ \\
\hline$\lambda^{2}$ & 9.1 & 38.6 & 87.8 & 157.0 & 245.9 & 354.6 \\
\hline
\end{tabular}

Table 2

Relative radii, $r / a$, of nodal circles for axisymmetric vibrations of a circular plate completely free and $v=1 / 3$ from Leissa and Narita (1980).

\begin{tabular}{llllllll}
\hline & r/a & & & & & \\
\hline$s 1$ & 0.680 & & & & & \\
$s 2$ & 0.842 & 0.391 & & & & \\
$s 3$ & 0.894 & 0.591 & 0.257 & & & \\
$s 4$ & 0.930 & 0.692 & 0.441 & 0.191 & & \\
$s 5$ & 0.954 & 0.753 & 0.550 & 0.352 & 0.154 & \\
$s 6$ & 0.958 & 0.794 & 0.642 & 0.456 & 0.292 & 0.131 \\
\hline
\end{tabular}

Table 3

NAVMI factors for axisymmetric vibrations of a free circular plate and $v=1 / 3$ with fluid on one side from Kwak (1991).

\begin{tabular}{lllllll}
\hline & $s 1$ & $s 2$ & $s 3$ & $s 4$ & $s 5$ & $s 6$ \\
\hline$\Gamma$ & 0.218247 & 0.137003 & 0.0962644 & 0.07401 & 0.06008 & 0.05056 \\
\hline
\end{tabular}

where $J_{n}$ is a Bessel function of the first kind, $I_{n}$ is a modified Bessel function of the first kind, $A_{n}$ and $C_{n}$ are the mode shape coefficients, $r$ is the radius and $\theta$ is the polar angle.

Each normal mode of a circular plate has $n$ nodal diameters and $s$ concentric nodal circles, which are the solutions to Eq. (6). For the axisymmetric vibrations and $v=1 / 3$, Leissa and Narita (1980) reports the natural frequency results of a circular plate completely free in terms of the roots, $\lambda^{2}$, indicated in Table 1 and defined as

$$
\lambda^{2}=\omega a^{2} \sqrt{\rho_{A} / D}
$$

where $a$ is the plate radius and $s 1$ to $s 6$ refers to the number of nodal circles from 1 to 6 of the corresponding mode. For each mode shape, the corresponding relative radii, $r$ / $a$, of the nodal circles as presented in Leissa and Narita (1980) are indicated in Table 2. In particular, the values from $s 1$ to $s 5$ are the average between computed and experimental results, meanwhile the values for $s 6$ are radii determined experimentally.

Kwak and Kim (1991) presented an analytical approach to quantify the change in the theoretical natural frequencies when the plate is immersed in water. They stated that the ratio between the frequencies in air and in water is a function of the supposed added virtual mass incremental (AVMI) factor, $\beta$, which reflects the increase in inertia due to the presence of the fluid and is expressed by

$$
\beta=\Gamma\left(\rho_{f} / \rho_{p}\right)(a / h)
$$

where $\rho_{f}$ is the density of the fluid, $\rho_{p}$ is the mass density of the plate, $a$ is the plate radius, $h$ is the plate thickness and $\Gamma$ is the non-dimensional added virtual mass incremental (NAVMI) factor.

The NAVMI factor was computed by Kwak (1991) assuming equivalent mode shapes for the plate in contact with water on one side and the plate in air, and the results are given in Table 3 for free circular plates and $v=1 / 3$. If the NAVMI factor is doubled, in the case of a fully immersed plate, the natural frequencies can be calculated using the following expression:

$$
f_{\text {fluid }}=\frac{f_{\text {vacuum }}}{\sqrt{1+\beta}}
$$

where $f_{\text {vacuum }}$ and $f_{\text {fluid }}$ are the plate frequencies in vacuum and immersed in a fluid, respectively.

\section{Experimental setup}

The circular Chladni plate had an outer radius, $a$, of $0.12 \mathrm{~m}$ and a thickness, $h$, of $0.8 \cdot 10^{-3} \mathrm{~m}$. The plate was made of T6 temper 6061 aluminium alloy with a density, $\rho_{p}$, of $2700 \mathrm{~kg} / \mathrm{m}^{3}$, a Young's modulus, $E$, of $69 \mathrm{GPa}$ and a Poisson's ratio, $v$, of 0.35 . For clamping purposes, the plate had a small hole at its centre with a diameter of $4 \cdot 10^{-3} \mathrm{~m}$.

The experimental setup shown in Fig. 1 comprises a square tank with transparent walls, a mechanical wave driver and a function generator. The tank was made of Plexiglass and had the following parameters: $\rho=1190 \mathrm{~kg} / \mathrm{m}^{3}, E=3.3 \mathrm{GPa}$ and $v=0.37$. The wall thickness was $0.01 \mathrm{~m}$, and the inner dimensions of the tank were $0.48 \times 0.48 \times 0.49 \mathrm{~m}^{3}$. The mechanical wave driver was a long throw speaker with an attached drive arm. The speaker was capable of vibrating at frequencies of $0.1 \mathrm{~Hz}$ to $5 \mathrm{kHz}$ and amplitudes of up to 7 millimetres $(\mathrm{mm})$ peak-to-peak at the low end of the frequency range. The function generator was capable of producing sinusoidal waveforms from $0.2 \mathrm{~Hz}$ to $2 \mathrm{MHz}$. 


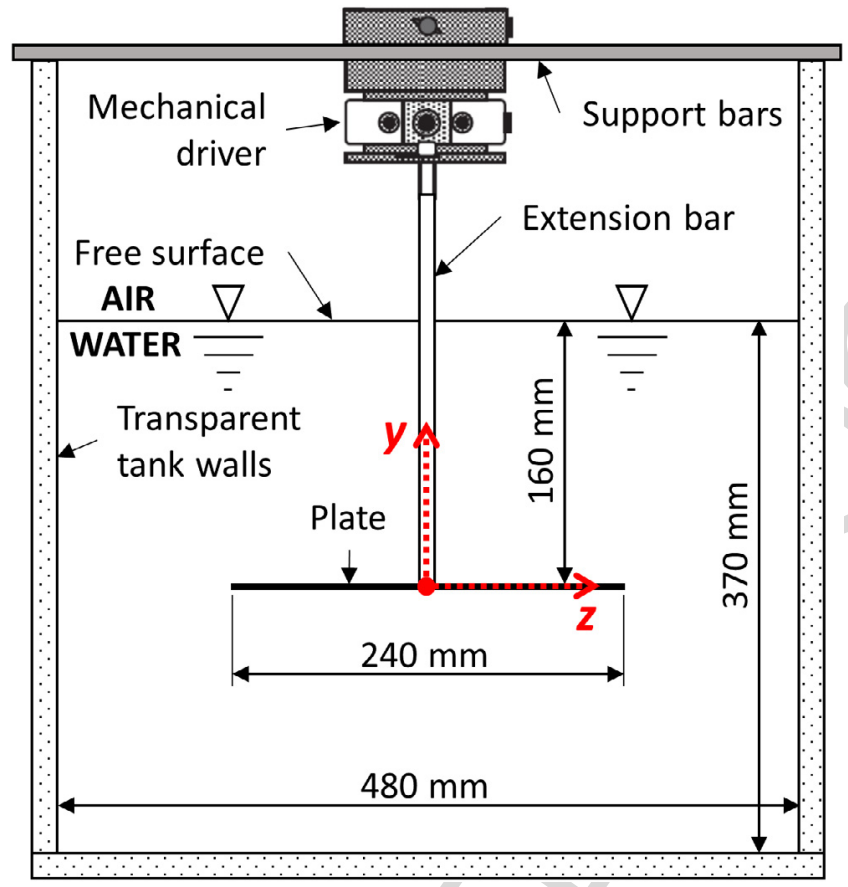

Fig. 1. Schematic of the experimental setup with the plate submerged in a water tank.

The mechanical drive was mounted in an inverted position at the top of the tank and rested on horizontal steel bars that were supported by the lateral walls of the tank; this arrangement allowed for plate submersion while keeping the driver out of the water. There was a cylindrical extension bar that connected the plate to the drive arm, and a screw fastened the bar to the plate. The other end of the bar was secured to the driver arm with hose clamps. The bar was made of aluminium with a length of $0.2 \mathrm{~m}$, a diameter of $8 \cdot 10^{-3} \mathrm{~m}$ and a mass of $0,027 \mathrm{~kg}$. This extension allowed to submerge the plate $0.16 \mathrm{~m}$ below the free surface, which corresponds to a submergence ratio of 1.33 relative to the plate radius. Based on the results obtained by Amabili (1996) for axisymmetric modes of simply supported circular plates, free surface effects might be negligible at least for the modes with more than 1 nodal circle.

The cylindrical coordinate reference system adopted in the current study is indicated in Figs. 1 and 2. The transverse direction (height) of the plate corresponds to the $y$-axis and the radial direction corresponds to the $z$-axis. Consequently, the mechanical drive exerted a sinusoidal driving force to the plate in the $y$-direction.

\section{Numerical model}

\section{1. acoustic-structural FEA}

The governing equations of the coupled acoustic-structural analysis include the structural dynamics equation along with the Navier-Stokes (NS) conservation of mass and momentum equations. The program makes the following assumptions: the fluid is compressible and irrotational, there is no body force, the pressure disturbance of the fluid is small with respect to the mean pressure and there is no mean flow of the fluid.

Using the previous assumptions and considering viscous dissipation, the NS equations can be simplified to obtain the lossy acoustic wave equation for a harmonically varying pressure

$$
\nabla\left(\frac{1}{\rho_{0}} \nabla p\right)+\frac{\omega^{2}}{\rho_{0} c^{2}} p+j \omega \nabla\left[\frac{4 \mu}{3 \rho_{0}} \nabla\left(\frac{1}{\rho_{0} c^{2}} p\right)\right]=-j \omega\left(\frac{Q}{\rho_{0}}\right)+\nabla\left[\frac{4 \mu}{3 \rho_{0}} \nabla\left(\frac{Q}{\rho_{0}}\right)\right]
$$

where $c$ is the speed of sound in the fluid, $\rho_{0}$ is the mean fluid density, $\mu$ is the dynamic viscosity, $Q$ is the mass source in the continuity equation, $t$ is time, $p$ is the acoustic pressure amplitude and $\omega$ is the acoustic pressure angular frequency.

The finite element formulation of Eq. (11) is obtained by testing wave using the Galerkin procedure. After derivation, the discretized wave equation in matrix notation is

$$
\mathbf{M}_{\mathrm{F}} \ddot{\mathbf{p}}_{\boldsymbol{e}}+\mathbf{C}_{\mathrm{F}} \dot{\mathbf{p}}_{\boldsymbol{e}}+\mathbf{K}_{\mathrm{F}} \mathbf{p}_{\boldsymbol{e}}+\bar{\rho}_{0} \mathbf{R}^{\mathrm{T}} \ddot{\mathbf{u}}_{\boldsymbol{e}, \mathbf{F}}=\mathbf{f}_{\mathrm{F}}
$$



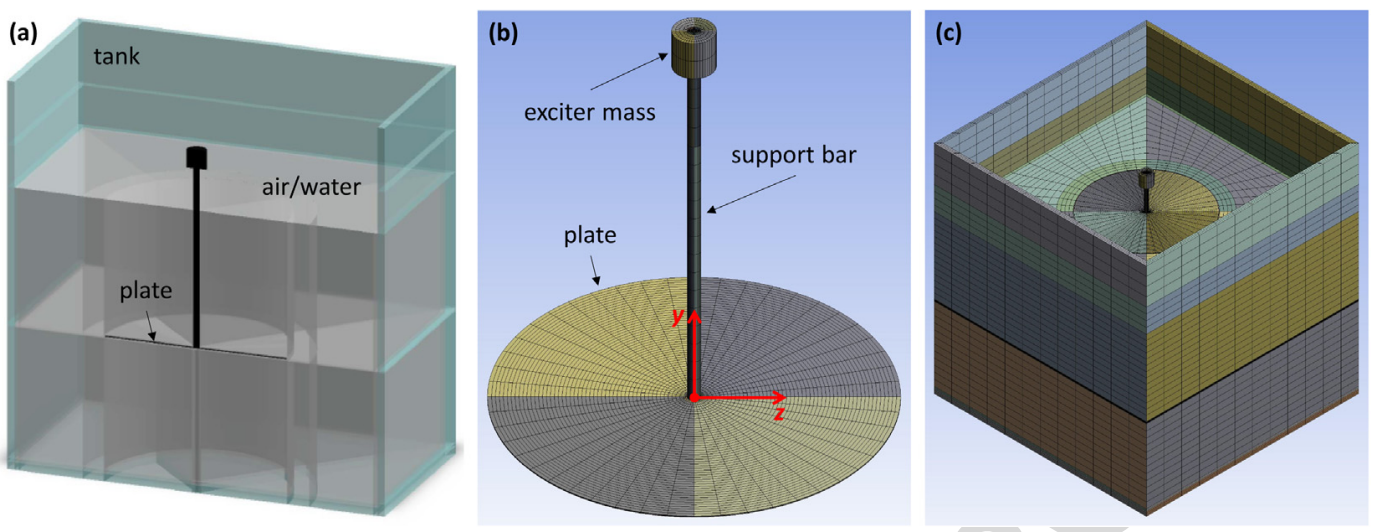

Fig. 2. Section of the model showing the fluid and structure domains (a), plate mesh and support system (b) and the mesh of the complete model (c).

where $\mathbf{p}_{\mathbf{e}}$ is the nodal acoustic pressure vector, $\mathbf{u}_{\mathbf{e}, \mathbf{F}}$ is the nodal displacement vector, $\mathbf{f}_{\mathbf{F}}$ is the acoustic fluid load vector, and $\mathbf{M}_{\mathbf{F}}, \mathbf{C}_{\mathbf{F}}, \mathbf{K}_{\mathbf{F}}$ and $\mathbf{R}$ are the acoustic fluid mass, fluid damping, fluid stiffness and fluid boundary matrices, respectively.

The coupling conditions on the interface, $\Gamma_{I}$, between the acoustic fluid and the structure are given by

$$
\begin{aligned}
\overline{\bar{\sigma}}\left(\mathbf{u}_{\mathbf{S}}\right) \mathbf{n}+p \mathbf{n} & =0 \\
\mathbf{n} \cdot \mathbf{u}_{\mathbf{S}}-\mathbf{n} \cdot \mathbf{u}_{\mathbf{F}} & =0
\end{aligned}
$$

where $\overline{\overline{\boldsymbol{\sigma}}}\left(\mathbf{u}_{\mathbf{s}}\right)$ is the solid stress tensor, $\mathbf{u}_{\mathbf{s}}$ is the solid displacement vector, $\mathbf{u}_{\mathbf{F}}$ is the acoustic fluid displacement vector and $\mathbf{n}$ is the outward normal unit vector of the fluid domain.

The discretized structural and lossy wave equations are then combined to obtain the unsymmetrical coupled FSI matrix system

$$
\left[\begin{array}{cc}
\mathbf{M}_{\mathbf{S}} & 0 \\
\bar{\rho}_{0} \mathbf{R}^{\mathbf{T}} & \mathbf{M}_{\mathbf{F}}
\end{array}\right]\left\{\begin{array}{l}
\ddot{\ddot{u}}_{\mathbf{e}} \\
\ddot{\mathbf{p}}_{\mathbf{e}}
\end{array}\right\}+\left[\begin{array}{cc}
\mathbf{C}_{\mathbf{S}} & 0 \\
0 & \mathbf{C}_{\mathbf{F}}
\end{array}\right]\left\{\begin{array}{l}
\dot{\mathbf{u}}_{\mathbf{e}} \\
\dot{\mathbf{p}}_{\mathbf{e}}
\end{array}\right\}+\left[\begin{array}{cc}
\mathbf{K}_{\mathbf{s}} & -\mathbf{R} \\
0 & \mathbf{K}_{\mathbf{F}}
\end{array}\right]\left\{\begin{array}{l}
\mathbf{u}_{\mathbf{e}} \\
\mathbf{p}_{\mathbf{e}}
\end{array}\right\}=\left\{\begin{array}{l}
\mathbf{f}_{\mathbf{S}} \\
\mathbf{f}_{\mathbf{F}}
\end{array}\right\}
$$

where $\mathbf{M}_{\mathbf{S}}, \mathbf{C}_{\mathbf{S}}$ and $\mathbf{K}_{\mathbf{S}}$ are the structure solid mass, damping and stiffness matrices, respectively, and $\mathbf{f}_{\mathbf{S}}$ is the structure load vector.

\subsection{Model and sensitivity analysis}

The coupled model comprises one acoustic fluid domain, either air or water, and two structure solid domains corresponding to the aluminium plate and the Plexiglass tank. To model the mechanical exciter and the supporting system, a cylindrical mass at the top of the plate supporting bar was considered, as shown in Fig. 2. Particular attention was given to simulate the bolted joint between the plate and the support arm bodies, which was done with a beam-type connector.

A complex geometry with 231 bodies was created to build an axisymmetric mesh for the entire model, with high mesh density at the plate and surrounding fluid and low mesh density further from the plate. Based on local mesh controls, the model contained 147120 higher order hexahedral elements that were defined with quadratic pressure or displacement behaviour. The nodes in the elements had four degrees of freedom, including the translations in the nodal directions and pressure for the fluid domain. Moreover, to reduce the number of equations in the model, a single layer of elements was created at the plate-fluid boundary and the tank-fluid boundary. Then, the coupled algorithm was only used in these two acoustic domains. For the remaining fluid elements, an uncoupled algorithm was used to account for only the pressure behaviour.

The boundary condition defined for the bottom surfaces of the tank in contact with the ground was zero displacement in all directions. The boundary condition defined for the free surface elements was zero pressure.

A series of modal analyses were solved to identify the axisymmetric modes of vibration in a wide range of frequencies. Then, harmonic response analyses were carried out for the modes of interest; a sinusoidal vertical force, $F y$, of $1 \mathrm{~N}$ was applied to the exciter mass, which restricted any radial displacement of the lateral walls. The material properties considered in the calculations are listed in Table 4. The numerical results in air were adjusted to the experimental ones by tuning the exciter mass. As a result, a total mass of about $0,08 \mathrm{~kg}$ was considered for the bar and the exciter together.

The independence of the results on the mesh characteristics were verified by increasing the number of elements and checking for the stability of the natural frequencies. Finally, it was concluded that the adequate number of plate divisions in the radial, angular and axial directions should be 50, 48 and 2, respectively, as shown in Fig. 2. For the surrounding fluid domain, the same radial and angular divisions were used. 


\section{ARTICLE IN PRESS}

Table 4

Material properties considered in the numerical model.

\begin{tabular}{|c|c|c|c|c|}
\hline Material & Density $\left[\mathrm{kg} / \mathrm{m}^{3}\right]$ & Sonic speed [m/s] & Young modulus [GPa] & Viscosity [Pa s] \\
\hline Aluminium & 2700 & - & 69 & - \\
\hline Plexiglas & 1190 & - & 3.3 & - \\
\hline Water & 998 & 1482 & - & $1.002 \cdot 10^{-3}$ \\
\hline Air & 1.2041 & 343.24 & - & $1.821 \cdot 10^{-5}$ \\
\hline
\end{tabular}

Table 5

Natural frequencies of axisymmetric modes of vibration for a circular plate completely free in vacuum, air and water. Theoretical values (th) in vacuum based on Leissa and Narita (1980) and in air and in water based on Kwak (1991); simulated values (sim) obtained with ANSYS ${ }^{\circledR}$; and percent deviations ( $\mathrm{dev}$ ) of simulated values relative to the theoretical ones.

\begin{tabular}{|c|c|c|c|c|c|c|}
\hline Mode & $s 1$ & $s 2$ & $s 3$ & $s 4$ & $s 5$ & $s 6$ \\
\hline$f_{\text {vacuum th }}[\mathrm{Hz}]$ & 125.1 & 531.0 & 1209.4 & 2162.6 & 3387.2 & 4884.5 \\
\hline$f_{\text {vacuum } \operatorname{sim}}[\mathrm{Hz}]$ & 125.0 & 531.0 & 1210.0 & 2160.0 & 3380.0 & 4869.0 \\
\hline $\operatorname{dev}[\%]$ & -0.1 & 0.0 & 0.0 & -0.1 & -0.2 & -0.3 \\
\hline$f_{\text {air th }}[\mathrm{Hz}]$ & 123.3 & 526.1 & 1201.6 & 2151.8 & 3373.4 & 4867.7 \\
\hline$f_{\text {air } \operatorname{sim}}[\mathrm{Hz}]$ & 123.2 & 525.7 & 1201.4 & 2144.9 & 3364.0 & 4840.0 \\
\hline $\operatorname{dev}[\%]$ & -0.1 & -0.1 & 0.0 & -0.3 & -0.3 & -0.6 \\
\hline$f_{\text {water th }}[\mathrm{Hz}]$ & 24.7 & 130.8 & 351.0 & 707.0 & 1214.0 & 1885.7 \\
\hline$f_{\text {water sim }}[\mathrm{Hz}]$ & 27.2 & 139.2 & 365.7 & 727.5 & 1240.8 & 1918.7 \\
\hline $\operatorname{dev}[\%]$ & 11.3 & 6.4 & 4.2 & 2.9 & 2.2 & 1.7 \\
\hline
\end{tabular}

\subsection{Model validation}

For validation purposes, the model described in the previous section was simplified to simulate the axisymmetric modes of vibration of a completely free circular plate. Both the mechanical exciter and the Plexiglass reservoir bodies were suppressed and the supporting bar body was modelled as a fluid instead of a solid. As a result, the plate was fully surrounded by fluid elements and its motion was unrestricted. All the outer fluid walls were set to zero pressure. Specifically for vacuum conditions, the acoustic elements were also suppressed and only the structural elements were considered. In summary, the accuracy was checked by comparing the numerical results with the data in vacuum based on Leissa and Narita (1980) and in air and in water based on Kwak (1991) presented in Section 2.

In our particular case, the plate flexural rigidity was $D=3.355 \mathrm{~N} \mathrm{~m}$ and the area density was $\rho_{A}=2.16 \mathrm{~kg} / \mathrm{m}^{2}$. Therefore, the corresponding angular frequency in rad/s was obtained from Eq. (7) as

$$
\omega=86.548 \lambda^{2} .
$$

Using Eq. (15) and the values indicated in Table 1, the theoretical natural frequencies of the plate in a vacuum, $f_{\text {vacuum }}$ th, were calculated and expressed in Hz. Then, using Eqs. (8) and (9) with the double value of the NAVMI factors indicated in Table 3 and the properties indicated in Table 4 , the natural frequencies of the plate fully submerged in air, $f_{\text {air }}$ th, and in water, $f_{\text {water th }}$, were also calculated.

All these results are given in Table 5 for the six first axisymmetric modes of vibration ( $s 1$ to $s 6)$. The accuracy of the numerical results for both the vacuum and air conditions confirmed the model goodness-of-fit since the largest percent deviations relative to the theoretical values were around $0.6 \%$. A slight reduction of the natural frequencies was observed due to the air density as expected.

Considering the results of the plate in water, the natural frequencies were significantly reduced due to the fluid density indicating that the model reproduced the added mass effect. However, the simulated frequencies were slightly overestimated compared to theoretical ones. The deviations ranged from around $2 \%$ for the highest mode $s 6$ up to $11 \%$ for the lowest mode s1.

The nodal radii obtained numerically with a radial resolution of $6 \cdot 10^{-4} \mathrm{~m}$ for the total number of nodal circles ( $s 1$ to $s 6$ ) are indicated in Table 6 . It was found that the results for vacuum and air conditions presented deviations that in general terms were negligible for all the modes with the exception of few radii with maximum differences equal or less than $3.6 \%$. Conversely, larger deviations were found for the water results. Analogously to the natural frequency values, the differences of nodal radius values increased as the nodal number decreased, being maximum for the outer nodal radius of mode s1 with a deviation of about $11 \%$.

In general, the vacuum and air modes of vibration were well predicted by the numerical model. Meanwhile, the simulated water vibrations presented deviations in terms of frequencies and nodal radii. The maximum difference was found for the lowest mode but the accuracy increased with mode order. Similarly, Kwak and Kim (1991) also reported that the calculated natural frequency of mode $s 1$ in water presented a difference of $10 \%$ relative to their experimental observation, which is close to the deviation found in our numerical simulation of $11.3 \%$. They also reported that the natural frequencies in air exhibited differences up to $8 \%$ with respect to the theoretical ones, which are significantly higher than the deviations of our numerical results that are less than $1 \%$. Moreover, they found that the corresponding mode $s 1$ in air and in water exhibited 
Table 6

Simulated normalized nodal radii of the free plate in vacuum, air and water, and percent deviations relative to the theoretical values in vacuum presented in Table 2 .

\begin{tabular}{|c|c|c|c|c|c|c|c|}
\hline Mode & Condition & $\mathrm{r} / \mathrm{a}$ & & & & & \\
\hline$s 1$ & $\begin{array}{l}\text { Vacuum } \\
\text { dev [\%] } \\
\text { Air } \\
\text { dev [\%] } \\
\text { Water } \\
\operatorname{dev}[\%]\end{array}$ & $\begin{array}{l}0.679 \\
-0.1 \\
0.677 \\
-0.5 \\
0.607 \\
-10.7\end{array}$ & & & & & \\
\hline$s 2$ & $\begin{array}{l}\text { Vacuum } \\
\text { dev [\%] } \\
\text { Air } \\
\text { dev [\%] } \\
\text { Water } \\
\operatorname{dev}[\%]\end{array}$ & $\begin{array}{l}0.841 \\
-0.1 \\
0.841 \\
-0.1 \\
0.794 \\
-5.8\end{array}$ & $\begin{array}{l}0.391 \\
-0.1 \\
0.391 \\
-0.1 \\
0.366 \\
-6.5\end{array}$ & & & & \\
\hline$s 3$ & $\begin{array}{l}\text { Vacuum } \\
\text { dev [\%] } \\
\text { Air } \\
\operatorname{dev~[\% ]~} \\
\text { Water } \\
\operatorname{dev}[\%]\end{array}$ & $\begin{array}{l}0.893 \\
-0.1 \\
0.893 \\
-0.1 \\
0.861 \\
-3.7\end{array}$ & $\begin{array}{l}0.592 \\
0.2 \\
0.592 \\
0.2 \\
0.567 \\
-4.0\end{array}$ & $\begin{array}{l}0.256 \\
-0.3 \\
0.256 \\
-0.3 \\
0.249 \\
-3.2\end{array}$ & & & \\
\hline$s 4$ & $\begin{array}{l}\text { Vacuum } \\
\text { dev [\%] } \\
\text { Air } \\
\text { dev [\%] } \\
\text { Water } \\
\text { dev [\%] }\end{array}$ & $\begin{array}{l}0.920 \\
-1.0 \\
0.918 \\
-1.3 \\
0.896 \\
-3.7\end{array}$ & $\begin{array}{l}0.692 \\
-0.1 \\
0.692 \\
-0.1 \\
0.672 \\
-2.9\end{array}$ & $\begin{array}{l}0.443 \\
0.4 \\
0.450 \\
2.1 \\
0.430 \\
-2.4\end{array}$ & $\begin{array}{l}0.192 \\
0.3 \\
0.184 \\
-3.6 \\
0.187 \\
-2.3\end{array}$ & & \\
\hline$s 5$ & $\begin{array}{l}\text { Vacuum } \\
\text { dev [\%] } \\
\text { Air } \\
\text { dev [\%] } \\
\text { Water } \\
\operatorname{dev}[\%]\end{array}$ & $\begin{array}{l}0.935 \\
-2.0 \\
0.935 \\
-2.0 \\
0.915 \\
-4.0\end{array}$ & $\begin{array}{l}0.751 \\
-0.2 \\
0.751 \\
-0.2 \\
0.736 \\
-2.2\end{array}$ & $\begin{array}{l}0.552 \\
0.4 \\
0.552 \\
0.4 \\
0.542 \\
-1.4\end{array}$ & $\begin{array}{l}0.353 \\
0.4 \\
0.353 \\
0.4 \\
0.343 \\
-2.5\end{array}$ & $\begin{array}{l}0.154 \\
0.1 \\
0.154 \\
0.1 \\
0.149 \\
-3.1\end{array}$ & \\
\hline$s 6$ & $\begin{array}{l}\text { Vacuum } \\
\text { dev [\%] } \\
\text { Air } \\
\text { dev [\%] } \\
\text { Water } \\
\text { dev }[\%]\end{array}$ & $\begin{array}{l}0.945 \\
-1.3 \\
0.945 \\
-1.3 \\
0.930 \\
-2.9\end{array}$ & $\begin{array}{l}0.794 \\
-0.1 \\
0.794 \\
-0.1 \\
0.781 \\
-1.6\end{array}$ & $\begin{array}{l}0.627 \\
-2.4 \\
0.634 \\
-1.2 \\
0.617 \\
-3.9\end{array}$ & $\begin{array}{l}0.458 \\
0.4 \\
0.458 \\
0.4 \\
0.453 \\
-0.7\end{array}$ & $\begin{array}{l}0.294 \\
0.5 \\
0.294 \\
0.5 \\
0.289 \\
-1.2\end{array}$ & $\begin{array}{l}0.129 \\
-1.3 \\
0.129 \\
-1.3 \\
0.124 \\
-5.1\end{array}$ \\
\hline
\end{tabular}

Modal Assurance Criterion (MAC) value of about 90\% which indicates small differences between the corresponding mode shapes.

To remove the possible influence of uncertainties in material properties and specimen imperfections in our results, the difference of deviations in water and air relative to vacuum conditions in terms of frequencies, $\operatorname{dev} f_{w a t e r}-\operatorname{dev} f_{\text {air }}$, and outer nodal radii, dev $r / a_{w a t e r}-\operatorname{dev} r / a_{a i r}$, were calculated and plotted on the same graph in Fig. 3. As a result, analogous 3rd order polynomial trends were observed and the absolute values of the deviations were very close to each other.

In conclusion, the numerical model can be considered valid and its results might be more accurate than the analytical approach from Kwak and Kim (1991). The reason is that these theoretical results are based on the simplifying hypothesis that the mode shapes in a dense fluid as water are exactly the same as in vacuum. In fact, the results reinforce the possibility that significant differences can exist.

\section{Experimental and numerical results}

For the plate tested in air, particular excitation frequencies resulted in clear and thin nodal circles of sand as shown in the top row of Fig. 4 with the exception of the first nodal pattern which resembled an annulus; the distinct nodal circles allowed for identification of the natural frequencies of the six first axisymmetric vibration modes ranging consecutively from one radius (s1) to six radii $(s 6)$.

For the plate submerged in water, the Chladni patterns are shown in the bottom row of Fig. 4. In this case, the same modes could be found with the exception of $s 1$. The first mode could not be clearly identified due to the difficulty of obtaining consistent and repeatable results. Such negative outcome could be explained by an insufficient submergence and the tuning effect of a tank sloshing mode close to $s 1$, since this mode is more prone to be affected by free surface waves as predicted by Amabili and Kwak (1999).

Regarding the numerical simulations, similar natural frequencies of the plate in air and in water were also obtained. The top views of the simulated mode shapes in air and in water for $s 1$ to $s 6$ are shown in Fig. 5. 


\section{ARTCLE IN PRESS}

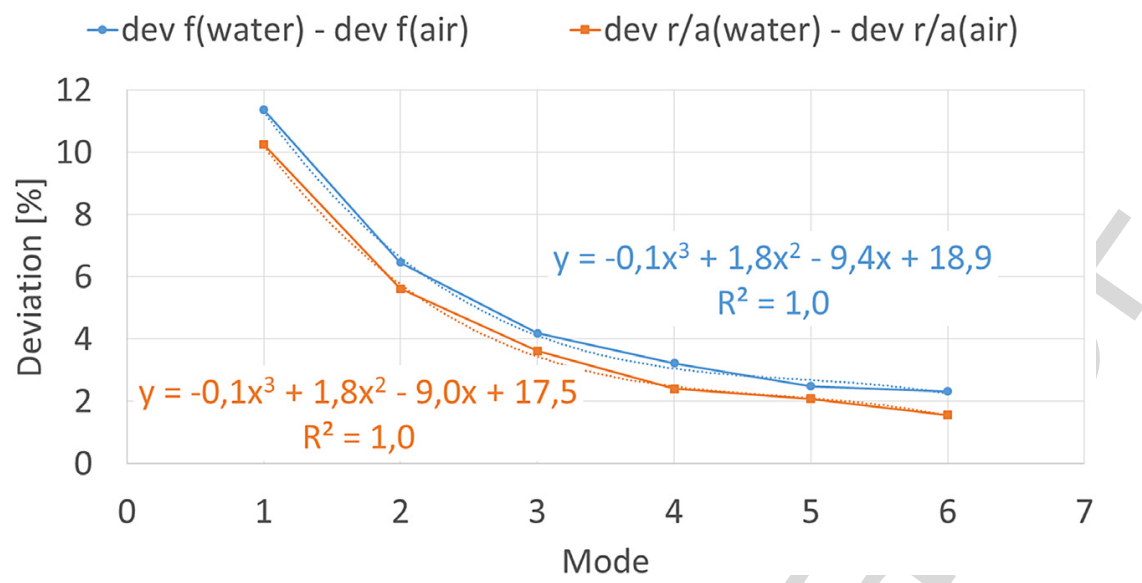

Fig. 3. Differences between the water and air deviations for natural frequencies and outer nodal radii of the axisymmetric modes from $s 1$ to $s 6$.
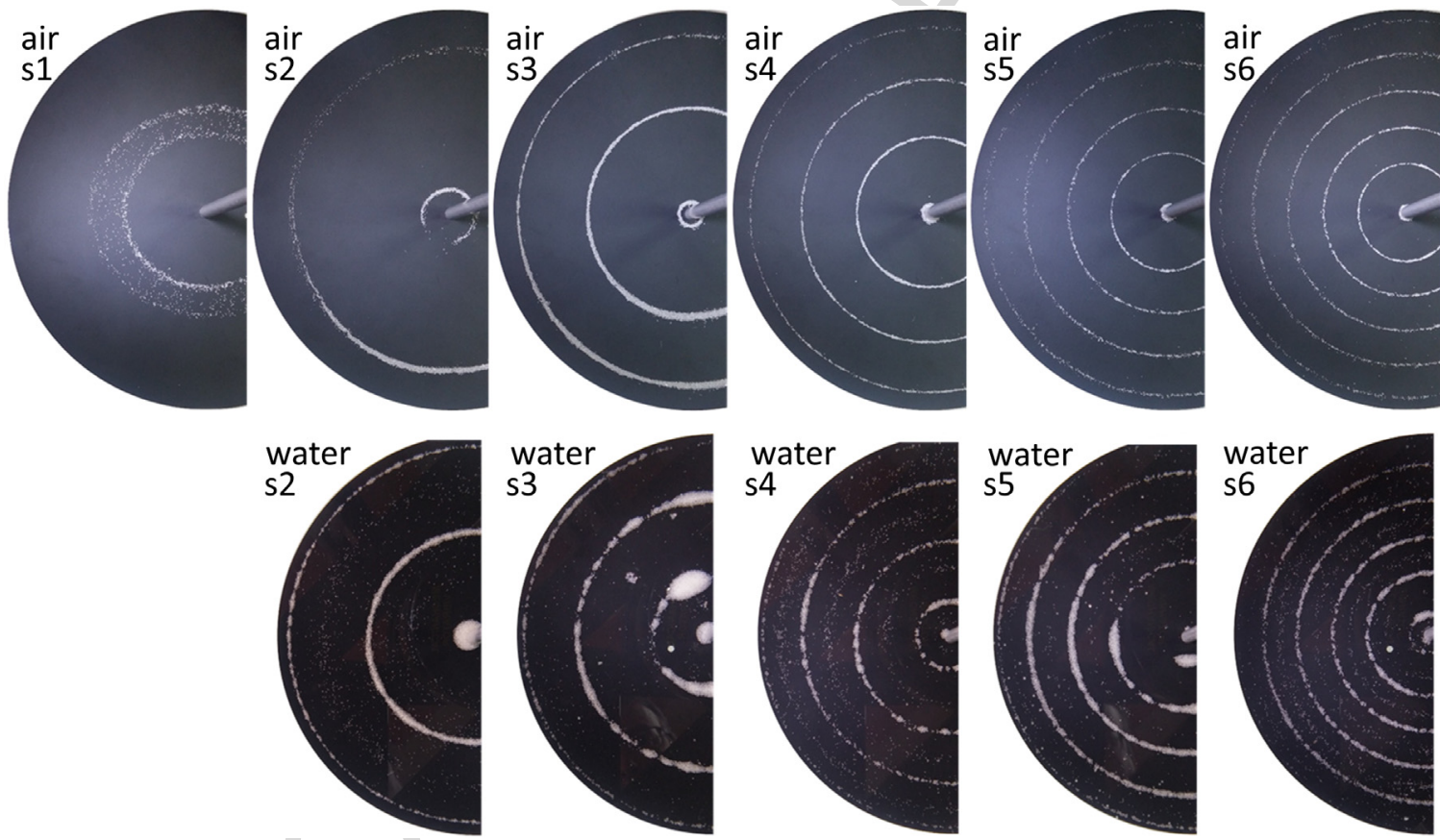

Fig. 4. Photographs of the Chladni patterns in air (top row) and in water (bottom row) for the axisymmetric modes of vibration with nodal radii from $s 1$ to $s 6$ (from left to right).

The averaged natural frequencies, $\bar{f}$, and the standard error of the mean, $\sigma_{\bar{f}}$, obtained after repeating several times the tests are indicated in Table 7, for air and water. The analogous natural frequencies calculated with the numerical model are also indicated in the same table. All these frequencies have been plotted in the graph to the left in Fig. 6 . The deviations of the simulated natural frequencies in air were no more than $0.6 \%$. For water, the accuracy of the simulated natural frequencies increased with mode order. The maximum numerical deviation was of about $2.4 \%$ for $s 2$.

The frequency reduction ratio, FRR, was calculated for each mode with Eq. (16) to quantify the added mass effect. The numerical and experimental FRRs are indicated in Table 10 and plotted in the graph to the right in Fig. 6. The average FRR considering all the modes is of about $64 \%$ (see Table 8 ).

$$
F R R=100 \frac{f_{\text {air }}-f_{\text {water }}}{f_{\text {air }}}
$$

For air, the numerical nodal radii presented in Table 9 indicated a good mode shape agreement with experimental results for most of the modes. The maximum deviations were found for the outer circles of the high order modes from $s 4$ and $s 6$. 

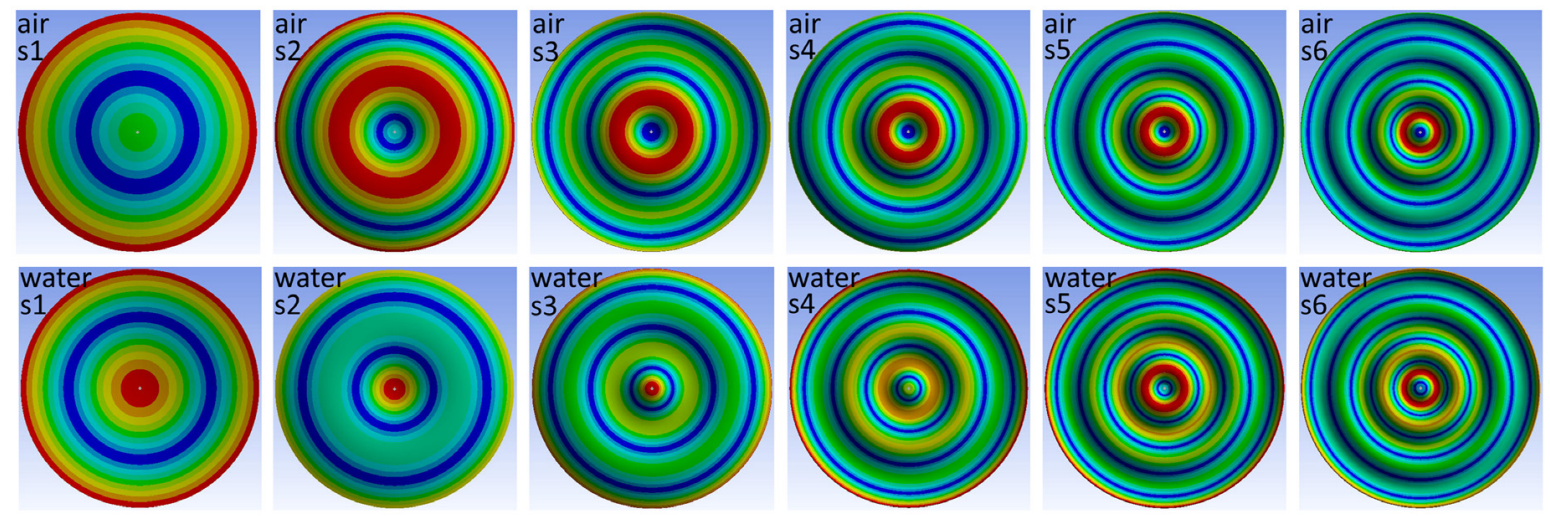

Fig. 5. Top views of the simulated mode shapes in air (top row) and in water (bottom row) for the axisymmetric modes of vibration with nodal radii from 1 to 6 (from left to right). Blue colour indicates zero deformation and red colour indicates maximum deformation. (For interpretation of the references to colour in this figure legend, the reader is referred to the web version of this article.)
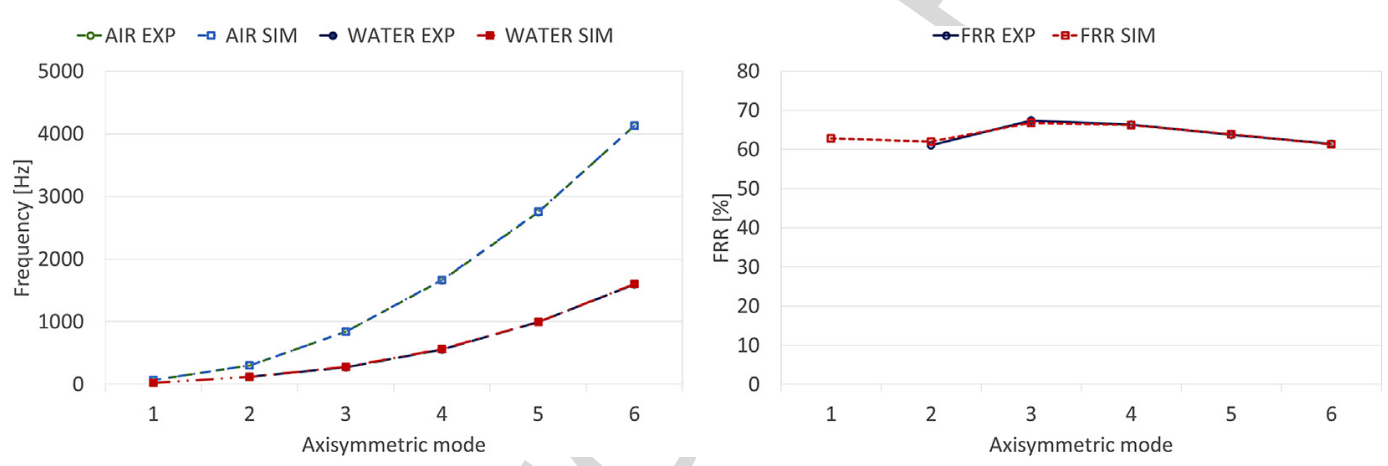

Fig. 6. Comparison of experimental and numerical natural frequencies and frequency reduction ratios (FRR) for the axisymmetric modes from $s 1$ to $s 6$.

Table 7

Experimental and simulated natural frequencies with corresponding percent deviations for air and water.

\begin{tabular}{|c|c|c|c|c|c|c|}
\hline & \multicolumn{3}{|l|}{ Air } & \multicolumn{3}{|l|}{ Water } \\
\hline & $\begin{array}{l}\overline{\operatorname{Exp}[\mathrm{Hz}]} \\
\bar{f}_{a} \pm \sigma_{\overline{\mathrm{f}}}\end{array}$ & $\begin{array}{l}\operatorname{Sim}[\mathrm{Hz}] \\
f_{a}\end{array}$ & $\operatorname{Dev}[\%]$ & $\begin{array}{l}\operatorname{Exp}[\mathrm{Hz}] \\
\bar{f}_{w} \pm \sigma_{\bar{f}}\end{array}$ & $\begin{array}{l}\operatorname{Sim}[\mathrm{Hz}] \\
f_{w}\end{array}$ & $\operatorname{Dev}[\%]$ \\
\hline$s 1$ & $70 \pm 0.4$ & 70 & 0.6 & - & 26 & - \\
\hline$s 2$ & $305 \pm 2.4$ & 305 & 0.0 & $119 \pm 3.1$ & 116 & -2.4 \\
\hline$s 3$ & $844 \pm 1.9$ & 846 & 0.2 & $275 \pm 5.9$ & 281 & 2.2 \\
\hline$s 4$ & $1657 \pm 3.4$ & 1666 & 0.5 & $558 \pm 6.3$ & 563 & 1.0 \\
\hline$s 5$ & $2747 \pm 5.1$ & 2756 & 0.3 & $997 \pm 5.8$ & 996 & -0.1 \\
\hline$s 6$ & $4129 \pm 10.3$ & 4130 & 0.0 & $1594 \pm 10.9$ & 1599 & 0.3 \\
\hline
\end{tabular}

Table 8

Experimental and numerical frequency reduction ratios between air and water, and differences.

\begin{tabular}{llll}
\hline FRR [\%] & exp & sim & Difference \\
\hline$s 1$ & - & 63 & - \\
$s 2$ & 61 & 62 & 1 \\
$s 3$ & 67 & 67 & 0 \\
$s 4$ & 66 & 66 & 0 \\
$s 5$ & 64 & 64 & 0 \\
$s 6$ & 61 & 61 & 0 \\
\hline
\end{tabular}

The reason for that is the accumulation of sand close to the supporting bar which prevented the precise identification of the nodal circle location, as it can be seen on the photographs in Fig. 4. 


\section{ARTICLE IN PRESS}

Table 9

Experimental and numerical normalized nodal radii in air, and percent deviations.

\begin{tabular}{|c|c|c|c|c|c|c|c|}
\hline & Air & & & $\mathrm{r} / \mathrm{a}$ & $\mathrm{y}=0$ & & \\
\hline \multirow[t]{3}{*}{$s 1$} & exp & 0.456 & & & & & \\
\hline & $\operatorname{sim}$ & 0.457 & & & & & \\
\hline & $\operatorname{dev} \%$ & 0 & & & & & \\
\hline \multirow[t]{3}{*}{$s 2$} & exp & 0.813 & 0.132 & & & & \\
\hline & $\operatorname{sim}$ & 0.801 & 0.126 & & & & \\
\hline & $\% \operatorname{dev}$ & -1 & -5 & & & & \\
\hline \multirow[t]{3}{*}{$s 3$} & exp & 0.873 & 0.526 & 0.063 & & & \\
\hline & $\operatorname{sim}$ & 0.876 & 0.523 & 0.060 & & & \\
\hline & $\% \mathrm{dev}$ & 0 & -1 & -5 & & & \\
\hline \multirow[t]{3}{*}{$s 4$} & exp & 0.907 & 0.652 & 0.375 & 0.050 & & \\
\hline & $\operatorname{sim}$ & 0.907 & 0.656 & 0.378 & 0.046 & & \\
\hline & $\% \mathrm{dev}$ & 0 & 1 & 1 & -7 & & \\
\hline \multirow[t]{3}{*}{ s5 } & exp & 0.926 & 0.727 & 0.513 & 0.295 & 0.044 & \\
\hline & $\operatorname{sim}$ & 0.934 & 0.735 & 0.510 & 0.298 & 0.033 & \\
\hline & $\% \mathrm{dev}$ & 1 & 1 & -1 & 1 & -25 & \\
\hline \multirow[t]{3}{*}{$s 6$} & exp & 0.939 & 0.778 & 0.602 & 0.422 & 0.245 & 0.041 \\
\hline & $\operatorname{sim}$ & 0.940 & 0.781 & 0.603 & 0.424 & 0.245 & 0.033 \\
\hline & $\% \operatorname{dev}$ & 0 & 0 & 0 & 1 & & -20 \\
\hline
\end{tabular}
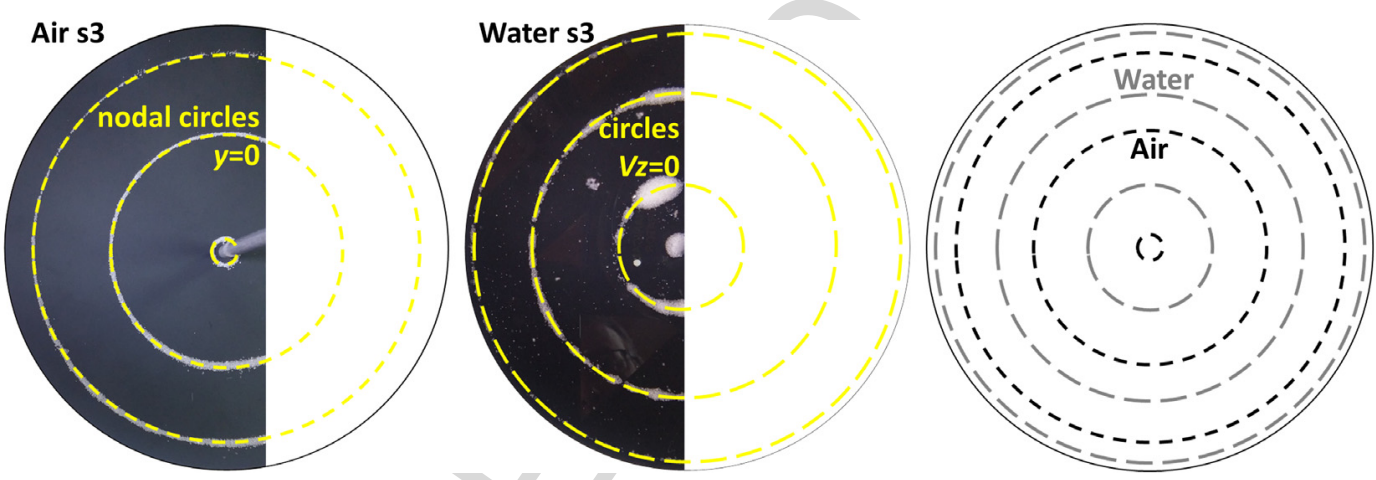

Fig. 7. Comparison of circles in air and in water for the axisymmetric mode of vibration with 3 nodal radii.

\section{Inverse Chladni patterns}

When comparing the sand patterns, it was observed that the circles in water were not located at the expected nodal radii. In fact, they were rather apart as shown in the illustration to the right of Fig. 7 where the visualized circles of mode $s 3$ in air and in water have been overlapped.

To solve this issue, a bibliographical search revealed that Chladni and other scientists had observed the tendency of light particles under resonance to move to the antinodes instead of the nodal lines although this phenomenon is less frequently stated. Van Gerner et al. (2011) reported that the inverse Chladni pattern is due to air currents induced by the plate vibrations, which is referred to as acoustic streaming (Lighthill, 1978). The use of direct numerical simulations (DNS) showed that the averaged Lagrangian velocity field (the velocity of tracer particles following the flow of air) is directed towards the antinodes where the amplitude of the standing wave is maximum. However, for the particular streaming that causes the inverse patterns, it is considered more appropriate to use the term "steady streaming" from Riley (2001).

However, the location of the outermost circles for all modes in water (see for instance photograph at the centre of Fig. 7) casted doubts on the assumption that they should be located at the antinodes where the maximum amplitude of the standing wave exists, as reported by Van Gerner et al. (2011). To clarify this point, the numerical results were used to calculate the radial, $V z$, and transversal, $V y$, acoustic velocities of the fluid elements just above the plate along a radius (recall coordinate system indicated in Figs. 1 and 2). These results were then compared with the transversal deformations, $y$, of the solid elements immediately below them. It was found that the circles in water were in close agreement with the relative radii for $V z=0$ obtained numerically as demonstrated by the results presented in Table 10 , and that these locations were slightly different from the antinode circles. As an example, the acoustic radial and transversal velocities just above the plate and the transversal deformation for mode $s 3$ are plotted for comparison in Fig. 8.

In conclusion, the close agreement between both sets of data validated the assumption that the experimental water-plate coupling generates an acoustic flow field that directs the solid particles towards regions above the submerged plate where 
Table 10

Normalized radii of experimental Chladni circles and numerical circles with zero transversal acoustic velocities in water, and percent deviations between them.

\begin{tabular}{|c|c|c|c|c|c|c|c|}
\hline & \multicolumn{3}{|l|}{ Water } & \multirow[t]{4}{*}{$\mathrm{r} / \mathrm{a}$} & \multicolumn{2}{|l|}{$\mathrm{Vz}=0$} & \\
\hline \multirow[t]{3}{*}{$s 1$} & $\exp$ & - & & & & & \\
\hline & $\operatorname{sim}$ & 0.881 & & & & & \\
\hline & $\operatorname{dev} \%$ & - & & & & & \\
\hline \multirow[t]{3}{*}{$s 2$} & $\exp$ & 0.936 & 0.544 & & & & \\
\hline & $\operatorname{sim}$ & 0.934 & 0.536 & & & & \\
\hline & $\operatorname{dev} \%$ & 0 & -1 & & & & \\
\hline \multirow[t]{3}{*}{ s3 } & exp & 0.959 & 0.691 & 0.300 & & & \\
\hline & $\operatorname{sim}$ & 0.954 & 0.682 & 0.311 & & & \\
\hline & $\operatorname{dev} \%$ & -1 & -1 & 4 & & & \\
\hline \multirow[t]{3}{*}{$s 4$} & exp & 0.965 & 0.763 & 0.487 & 0.182 & & \\
\hline & $\operatorname{sim}$ & 0.967 & 0.762 & 0.497 & 0.192 & & \\
\hline & dev \% & 0 & 0 & 2 & 6 & & \\
\hline \multirow[t]{3}{*}{ s5 } & $\exp$ & 0.970 & 0.815 & 0.596 & 0.374 & 0.133 & \\
\hline & $\operatorname{sim}$ & 0.974 & 0.815 & 0.603 & 0.391 & 0.139 & \\
\hline & dev \% & 0 & 0 & 1 & 4 & 5 & \\
\hline \multirow[t]{3}{*}{$s 6$} & $\exp$ & 0.981 & 0.850 & 0.669 & 0.488 & 0.308 & 0.103 \\
\hline & $\operatorname{sim}$ & 0.980 & 0.848 & 0.675 & 0.497 & 0.318 & 0.113 \\
\hline & $\operatorname{dev} \%$ & 0 & 0 & 1 & 2 & & 9 \\
\hline
\end{tabular}

$\rightarrow$-Radial vel. Vz $\rightarrow$-Transversal vel. Vy $\rightarrow$-Transversal def. y

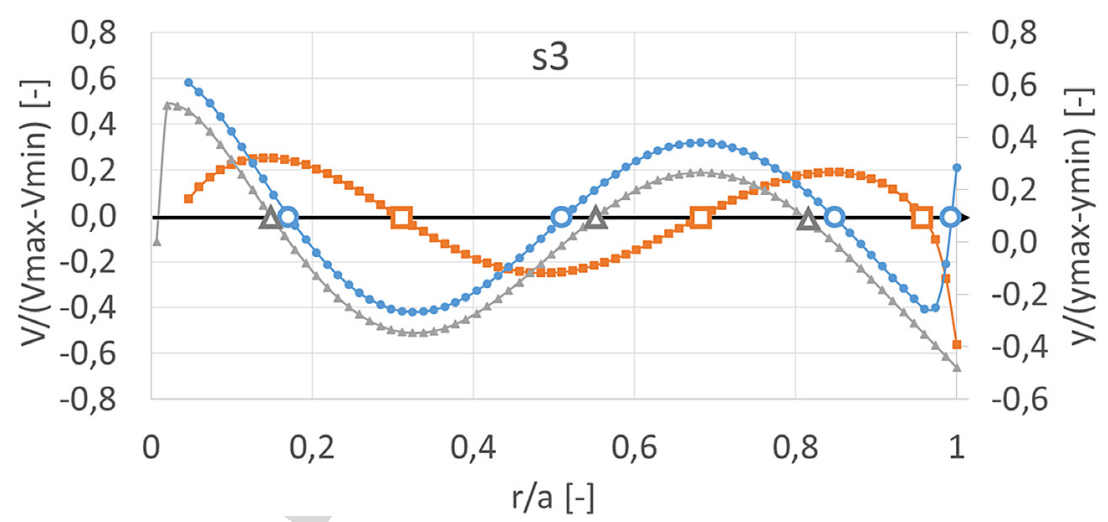

Fig. 8. Comparison of acoustic radial and transversal velocities just above the plate and transversal deformation of the plate along a radius for mode $s 3$ in water obtained with the numerical simulations (all values are normalized by their range).

the resulting radial velocity is zero. Furthermore, the simulated mode shapes in water can be assumed to be a valid reference to compare with the mode shapes in air.

\section{Effects of water loading on the mode shapes}

The effects of the plate submergence on the axisymmetric mode shapes were evaluated based only on the numerical results and measurable differences were found when the corresponding mode shapes in air and water were compared. For example, the 3D isometric views of the $s 3$ mode shapes in air and in water are plotted at the left side of Fig. 7. Then, the illustration at the right side of Fig. 7 displays the overlapped nodal circles for both cases. It can be seen that there is a slight decrease in the radii of the two outer nodal circles and a significant increase in the radius of the inner nodal circle when the plate is submerged in water, as marked with the arrows. Analogous trends occur for all the modes of vibration as it can be clearly observed when comparing in Fig. 10 the plate transversal deformations along a radius in air and in water. The normalized nodal radii determined from the horizontal axis positions where the deformation is zero and the percent deviations of radii in water relative to radii in air are presented in Table 11. These results indicate that due to the submergence, the innermost nodal radius of each mode will increase significantly at least 30\%, while the remaining outer circles will suffer around a $3 \%$ radius decrease. These mode shape changes are in agreement with the theoretical results of Amabili et al. (1995), Amabili et al. (1996), Amabili (1996) and Amabili and Kwak (1996) when comparing the predictions of the Rayleigh-Ritz method against the assumed-modes approach (see Fig. 9). 


\section{ARTICLE IN PRESS}
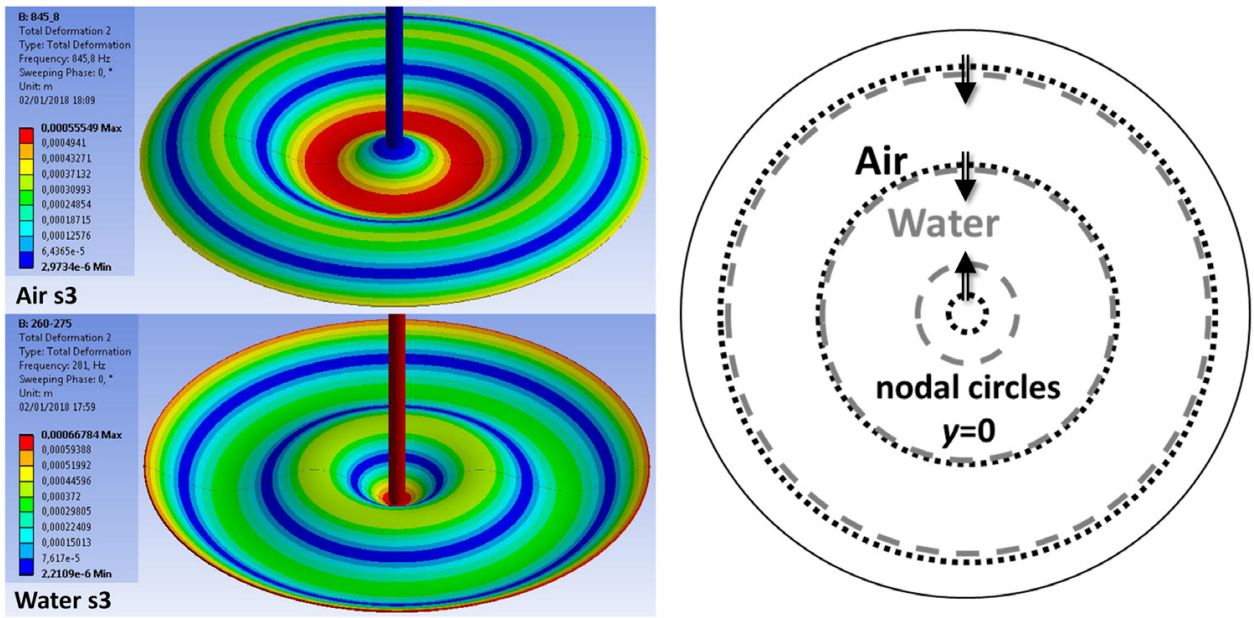

Fig. 9. 3D views of the simulated mode shapes in air and in water for the axisymmetric modes of vibration with 3 nodal radii (left) and comparison of the nodal circles in both cases (right). Arrows indicate direction of nodal line displacements from air to water.
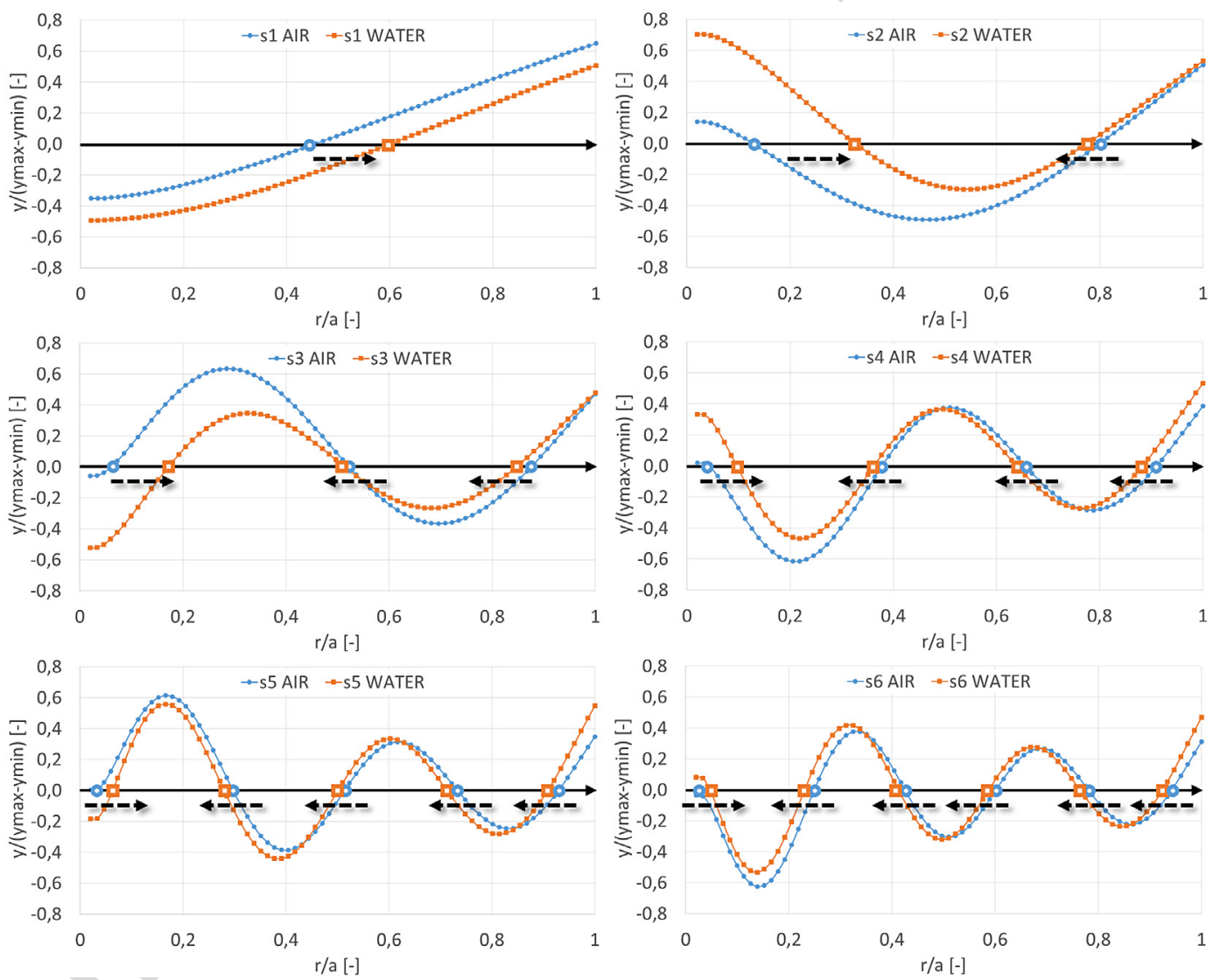

Fig. 10. Comparison of the air and water simulated transversal plate deformation along a radius for modes $s 1$ to $s 6$. Arrows indicate direction of nodal line displacement from air to water.

\section{Conclusions}

Experimental and numerical analyses were conducted to determine the effects of submergence on the axisymmetric natural frequencies and mode shapes of a circular plate free at its edge and excited at its centre through a cylindrical bar. 
Table 11

Normalized radii of simulated nodal circles in water (Fig. 10) and percent deviations relative to simulated air results (Table 10).

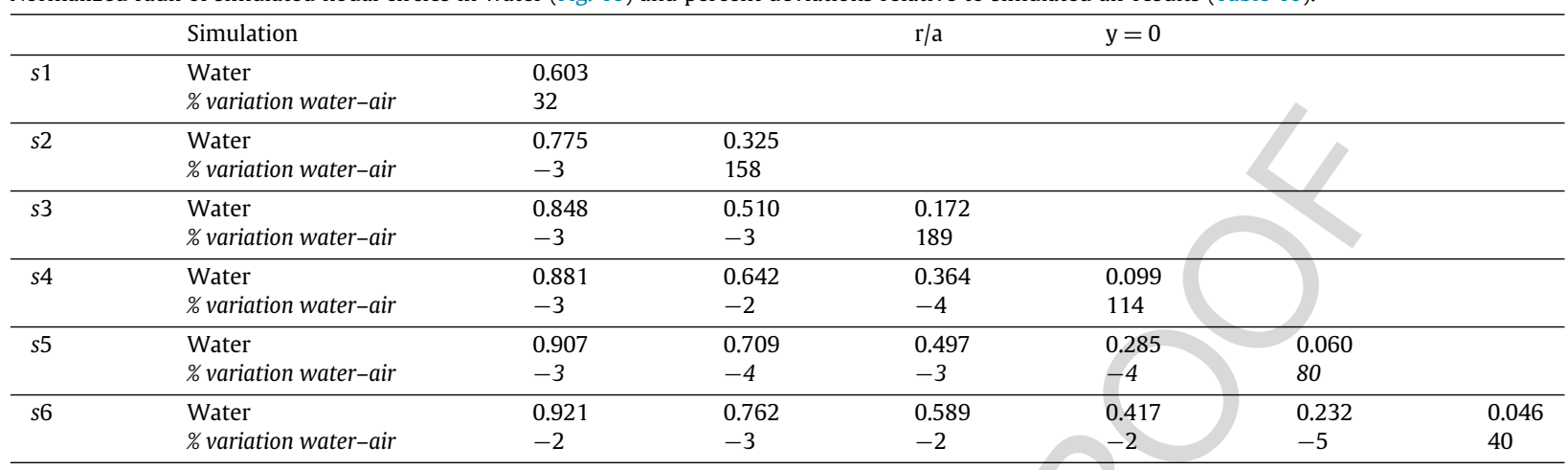

The Chladni patterns were visualized for each mode of vibration by scattered sand grains collected at nodal circles. A coupled acoustic fluid-structural finite element model was built for modal and full harmonic analyses. The model was validated against theoretical results of a free circular plate with the same dimensions and mechanical properties.

The experimental and numerical results obtained for the six first modes with a number of nodal radii from 1 to 6 were compared and a good agreement was found, thus confirming the accuracy of the model. The average frequency reduction ratio due to the added mass effects of water was found to be around $64 \%$.

When the plate was submerged in water, the solid particles were directed towards the circles with zero transversal acoustic velocities through the water currents generated by the plate displacement. Such behaviour differs from the observed air-induced inverse Chladni patterns that form at the antinodes when very light particles are used. The wet mode $s 1$ could not be clearly identified.

All mode shapes in water showed a significant increase in the innermost nodal radius and a slight decrease of all the rest of outer radii compared to the mode shapes in air. These results confirm that the modal coupling by water also modifies the mode shapes as predicted by Amabili et al. (1995), Amabili et al. (1996), Amabili (1996) and Amabili and Kwak (1996). Therefore, an acoustic-structural FSI simulation is a suitable and accurate tool to predict such effects in complex geometries when improved accuracy is required and enhanced applications are studied.

\section{Appendix A. Supplementary material}

Supplementary material related to this article can be found online at https://doi.org/10.1016/j.jfluidstructs.2018.07.017.

\section{References}

Amabili, M., 1996. Effect of finite fluid depth on the hydroelastic vibrations of circular and annular plates. J. Sound Vib. 193 (4), 909-925.

Amabili, M., Frosali, G., Kwak, M.K., 1996. Free vibrations of annular plates coupled with fluids. J. Sound Vib. 191 (5), 825-846.

Amabili, M., Kwak, M.K., 1996. Free vibration of circular plates coupled with liquids: revising the Lamb problem. J. Fluids Struct. 10 (7), $743-761$.

Amabili, M., Kwak, M.K., 1999. Vibration of circular plates on a free fluid surface: effect of surface waves. J. Sound Vib. 226 (3), 407-424.

Amabili, M., Pasqualini, A., Dalpiaz, G., 1995. Natural frequencies and modes of free-edge circular plates vibrating in vacuum or in contact with liquid. J. Sound Vib. 188 (5), 685-699.

Askari, E., Jeong, K.H., Amabili, M., 2013. Hydroelastic vibration of circular plates immersed in a liquid-filled container with free surface. J. Sound Vib. 332, 3064-3085.

Bergen, T.F., Pechersky, M.J., 1991. A modal analysis of submerged composite plates using digital speckle pattern interferometry, Technical report, University Park Applied Research Lab, Pennsylvania State University, pp. 1-183.

Blevins, R., 1979. Formulas for Natural Frequency and Mode Shape. Krieger publishing company, Florida.

Chladni, E., 1787. Entdeckungen über die Theorie des Klanges, Leipzig.

De La Torre, O., Escaler, X., Egusquiza, E., Farhat, M., 2013. Experimental investigation of added mass effects on a hydrofoil under cavitation conditions. J. Fluids Struct. 39, 173-187.

De La Torre, O., Escaler, X., Egusquiza, E., Farhat, M., 2014. Numerical and experimental study of a nearby solid boundary and partial submergence effects on hydrofoil added mass, Comput. \& Fluids $91,1-9$.

De La Torre, O., Escaler, X., Egusquiza, E., Farhat, M., 2016. Experimental mode shape determination of a cantilevered hydrofoil under different flow conditions. Proc. Inst. Mech. Eng. C 230 (19), 3408-3419.

Escaler, X., De La Torre, O., Goggins, J., 2017. Experimental and numerical analysis of directional added mass effects in partially liquid-filled horizontal pipes. J. Fluids Struct. 69, 252-264.

Garrido-Mendoza, C.A., Souto-Iglesias, A., Thiagarajan, K.P., 2013. Numerical simulation of hydrodynamics of a circular disk oscillating near a seabed. In: Proceedings of the ASME 2013 32nd International Conference on Ocean, Offshore and Arctic Engineering, OMAE2013, June 9-14, Nantes, France.

Gascón-Pérez, M., García-Fogeda, P., 2015. Induced damping on vibrating circular plates submerged in still fluid. Int. J. Appl. Mech. 07 (6), 1-18.

Jhung, M.J., Choi, Y.H., Ryu, Y.H., 2009. Free vibration analysis of circular plate with eccentric hole submerged in fluid. Nucl. Eng. Technol. 41 (3), $355-364$.

Junger, M.C., Feit, D., 1986. Sound, Structures, and Their Interaction, second ed. The MIT Press.

Kwak, M.K., 1991. Vibration of circular plates in contact with water. J. Appl. Mech. 58, 480-483.

Kwak, M.K., Amabili, M., 1999. Hydroelastic vibration of free-edge annular plates. Trans. ASME. J. Vib. Acoust. 121 (1), 26-32. 


\section{ARTICLE IN PRIESS}

Kwak, M.K., Kim, K.C., 1991. Axisymmetric vibration of circular plates in contact with fluid. J. Sound Vib. 146 (3), 381-389.

Lais, S., Liang, Q., Henggeler, U., Weiss, T., Escaler, X., Egusquiza, E., 2009. Dynamic analysis of Francis runners - experiment and numerical simulation. Int. J. Fluid Mech. Syst. 2 (4), 303-314.

Leissa, A.W., 1969. Vibration of plates, NASA SP (Scientific and Technical Information Division) 160.

Leissa, A.W., Narita, Y., 1980. Natural frequencies of simply supported circular plates. J. Sound Vib. 70 (2), 221-229.

Li, S., Karney, B.W., Liu, G., 2015. FSI research in pipeline systems-A review of the literature. J. Fluids Struct. 57, 277-297.

Lighthill, J., 1978. Acoustic streaming. J. Sound Vib. 61 (3), 391-418.

Lindholm, U.S., Kana, D.D., Chu, W.-H., Abramson, H.N., 1965. Elastic vibration characteristics of cantilever plates in water. J. Ship Res. 9 (1), 11-36.

Liu, X., Zhou, L., Escaler, X., Wang, Z., Luo, Y., De La Torre, O., 2017. Numerical simulation of added mass effects on a hydrofoil in cavitating flow using acoustic fluid-structure interaction. ASME J. Fluids Eng. 139 (4), 041301-041308.

Riley, N., 2001. Steady streaming. Annu. Rev. Fluid Mech. 33, 43-65.

Rodriguez, C.G., Egusquiza, E., Escaler, X., Liang, Q.W., Avellan, F., 2006. Experimental investigation of added mass effects on a Francis turbine runner in still water. J. Fluids Struct. 22 (5), 699-712.

Rossing, T.D., 1982. Chladni's law for vibrating plates. Amer. J. Phys. 50, 271-274.

Trivedi, C., Cervantes, M.J., 2017. Fluid-structure interactions in Francis turbines: A perspective review. Renewable Sustainable Energy Rev. 68 Part 1 , 87-101.

Van Gerner, H.J., van der Weele, K., van der Hoef, M.A., van der Meer, D., 2011. Air-induced inverse Chladni patterns. J. Fluid Mech. 689, $203-220$. 